\title{
A abordagem TXM para construção da marca de um laboratório universitário
}

\author{
The TXM approach to building a university lab brand
}

Caio Fraile Gonçalves, Marília Matos Gonçalves, Berenice Santos Gonçalves

Design, Identidade de marca, Branding, DNA da marca, TXM Branding.

A criação de marcas é atividade intrínseca do designer que, a partir da criatividade, torna-se um projetista em busca de soluções. Deste modo, o objetivo deste trabalho é analisar o uso de uma metodologia cocriativa para o design de marca do laboratório universitário e-biotech, que integra o Departamento de Engenharia Química e Engenharia de Alimentos da Universidade Federal de Santa Catarina (UFSC). A TXM Branding valoriza a cocriação entre a equipe de projeto, stakeholders e opinion makers para a elaboração de marcas. É composta pelas etapas Think ( $\mathrm{T})$, Experience $(\mathrm{X})$ e Manage $(\mathrm{M})$. No projeto apresentado neste artigo, foram empregadas apenas as etapas T e X. Mediante o desenvolvimento da pesquisa, a metodologia forneceu procedimentos que contribuíram com a organização do projeto, mostrando-se imprescindível na etapa de coleta e análise de informações. Desta forma, obteve-se uma marca harmoniosa, de construção moderna, inovadora, especialista, confiável, colaborativa e eco-friendly. Sendo assim, foi criada uma identidade visual coerente para o laboratório.

Design, Brand identity, Branding, Brand DNA, TXM Branding

The creation of brands is an intrinsic activity of the designer who, from creativity, becomes a designer in search of solutions. Thus, the objective of this work is to analyze the use of a co-creative methodology for the brand design of the university laboratory e-biotech, which integrates the Department of Chemical Engineering and Food Engineering at the Federal University of Santa Catarina - UFSC. TXM Branding values co-creation between the project team, stakeholders and opinion makers for the development of brands. It consists of the Think (T), Experience $(X)$ and Manage $(M)$ steps. In the project presented in this article, only steps $T$ and $X$ were used. Through the development of the research, the methodology provided procedures that contributed to the organization of the project, proving to be essential in the information collection and analysis stage. In this way, a harmonious brand was obtained, of modern construction, innovative, specialist, reliable, collaborative and eco-friendly. Therefore, a coherent visual identity was created for the laboratory.

\section{Introdução}

Em virtude dos avanços tecnológicos que possibilitaram a realização de novas configurações para toda uma gama de produtos, o conceito de design sofreu diversas transformações desde o século XX. Nos dias atuais o design envolve, para além da tradicional produção de objetos materiais, projetos nos quais os usuários interagem no ciberespaço por meio de interfaces gráfico digitais. (Quintão \& Triska, 2013, p. 105)

Anais do $10^{\circ} \mathrm{CIDI}$ e $10^{\circ} \mathrm{CONGIC}$

Kelli C.A.S. Smythe, Rafael de Castro Andrade (orgs.)

Sociedade Brasileira de Design da Informação - SBDI

Curitiba | Brasil | 2021
Proceedings of the $10^{\text {th }} \mathrm{CIDI}$ and $10^{\text {th }}$ CONGIC

Kelli C.A.S. Smythe, Rafael de Castro Andrade (orgs.)

Sociedade Brasileira de Design da Informação - SBDI Curitiba | Brazil | 2021 
Os consumidores atuais deixaram de ser apenas compradores de algum produto ou serviço, tornaram-se colecionadores de experiências, pois buscam, ao fazer uma nova aquisição, despertar em si mesmos novas sensações e emoções. O desejo de viver novas experiências, de adquirir bens que proporcionam qualidade sensitiva, simbólica e visual, faz com que as emoções estejam cada vez mais à frente de decisões de consumo. (Lipovetsky, 2016, p. 28).

As marcas possuem a característica de despertar emoções e sensações nos consumidores, pois quando conseguem construir vínculos sólidos com seu público, tendem a conquistá-los e a manter uma relação de preferência, uma vez que não se trata apenas da compra de um produto ou serviços, mas de uma experiência traduzida por um discurso sedutor. (Raposo \& Moura, 2019, p. 1386).

As marcas precisam tornar-se excêntricas, e, para isso, o uso do branding é uma ferramenta importante para a construção e visibilidade dos serviços ou produtos que as marcas oferecem. Neste caso, vale salientar que a gestão de uma marca e sua evolução quanto aos propósitos, design, objetivo, pontos fortes e pontos fracos, constituindo uma marca com forte potencial de representatividade. Por fim, pode-se ressaltar que, os consumidores procuram marcas que transparecem sensações, no qual eles consigam identificar fatores que façam com que os mesmos busquem conexões com as marcas. (Sutil et. al., 2019, p. 4).

A influência dos avanços tecnológicos repercutiu, segundo Costa $(2016$, p. 5) no que se refere à "ações e propostas de popularização da ciência, divulgação e interpretação do conhecimento científico". A autora completa dizendo que o modelo tradicional de divulgação científica, que ocorria por intermédio do jornalismo, foi remodelado para um formato no qual os pesquisadores pudessem assumir o protagonismo da disseminação do conhecimento. A marca possui papel fundamental nesse processo ao promover unidade, reconhecimento e distinção entre os laboratórios.

O e-biotech, Laboratório de Biotecnologia Ambiental, faz parte do Departamento de Engenharia Química e de Alimentos (EQA), pertencente ao Centro Tecnológico da Universidade Federal de Santa Catarina (UFSC) e estuda o desenvolvimento de processos que buscam diminuir impactos ambientais causados por resíduos industriais ou urbanos, sólidos ou líquidos. Desenvolve trabalhos com alunos de graduação e pós-graduação nas áreas de bioprocessos, remediação de solos contaminados e valorização de resíduos por meio de projetos de pesquisa e extensão.

A existência da marca do laboratório era conhecida apenas por uma parte de seus membros e não era utilizada por todos a quem fora apresentada. Em entrevista realizada com os alunos vinculados ao e-biotech, compreendeu-se que a marca que estava sendo utilizada havia sido elaborada sem estudos, não transparecendo o que o laboratório representa. Portanto, a ideia da criação de uma nova marca mostrou-se necessária para atingir o objetivo de dar ao laboratório maior visibilidade e representatividade.

Sendo assim, o objetivo deste artigo é analisar o uso de uma metodologia cocriativa para o design de marca do laboratório universitário e-biotech. Para tal, os procedimentos metodológicos contemplam revisão bibliográfica, seguida por um estudo de caso do laboratório e-biotech. 


\section{Design da informação e Marca}

O avanço dos meios digitais, principalmente no que compete às tecnologias da informação e comunicação, culminou em transformações no modo da sociedade se comunicar, relacionar, consumir e se informar, tornando a visualização e a interpretação dos dados uma tarefa complexa. Logo, define-se como premissa geral do Design da Informação a preocupação no processo e tratamento da informação, de forma a torná-la acessível a diferentes públicos.

A Sociedade Brasileira de Design da Informação (SBDI), define o design de informação como:

uma área do design gráfico que objetiva equacionar os aspectos sintáticos, semânticos e pragmáticos que envolvem os sistemas de informação através da contextualização, planejamento, produção e interface gráfica da informação junto ao seu público alvo. Seu princípio básico é o de otimizar o processo de aquisição da informação efetivado nos sistemas de comunicação analógicos e digitais." (SBDI, 2006)

Frascara (2004, p. 130) corrobora com o tema ao afirmar que "o design da informação consiste em duas etapas distintas: a organização da informação e o planejamento de sua apresentação visual". Dessa forma, tais tarefas exigem um conjunto de habilidades que contemplam o processamento, a organização e a apresentação das informações, de modo verbal e não verbal.

Em paralelo, o design concentra parte de seus estudos no que compete à conceituação e criação de identidades visuais, definida por Strunck (1989, p. 14) como o "sinal gráfico que, com o uso, passa a identificar um nome, ideia, produto ou serviço", visando transmitir e sintetizar seus ideais. Para tal, faz-se uso de um sistema que propõe a ordenação de todos os elementos que compõem o universo da marca, o Sistema de Identidade Visual (SIV).

Formam o sistema todos os veículos que veiculem os elementos básicos da identidade visual: 0 logotipo, o símbolo, a marca, as cores institucionais e o alfabeto institucional, além de outros eventuais elementos acessórios, que são aplicados em itens específicos (material de papelaria, letreiros, uniformes, sinalização, embalagens, gráfica ambiental etc). Estes veículos são chamados de aplicações. (Péon, 2003, p. 14)

Dessa forma, fica nítida a interseção do Design Gráfico, do ponto de vista da construção de identidades visuais, e do Design da Informação: enquanto o primeiro promove a identificação da marca no mercado ao promover originalidade à assinatura gráfica, o segundo se dedica a objetividade e compreensão das mensagens transmitidas pela marca a seu público (Raposo \& Moura, 2019, p. 1392).

\section{Metodologia projetual}

Metodologia pode ser definida como o conjunto de métodos, técnicas e ferramentas utilizados a fim de alcançar um determinado objetivo. No campo do design, surgiram métodos que orientavam o designer à solução de problemas de maneira ordenada. A metodologia projetual, como é conhecida, foi elucidada por Peón (2003, p. 50) como o "conjunto e a ordenação de 
procedimentos para a realização de um dado objetivo - ou seja, o conjunto de métodos utilizados, bem como o estudo e análise destes métodos". Por meio dela, é possível organizar as tarefas a serem realizadas pela equipe de design. Freitas et. al. (2013) complementa ao afirmar que uma:

metodologia projetual seja equivalente a um conjunto de procedimentos para o desenvolvimento de um determinado produto, onde estão relacionados nesse conjunto: a- métodos (caminho pelo qual se atinge um objetivo); b- técnicas, como habilidade para execução de determinada ação ou produtos; e c- ferramentas, como instrumentos ou utensílios empregados no cumprimento desta ação. (Freitas et. al. 2013, p. 3).

Relevante no contexto atual da teoria e prática do design, a cocriação ou colaboração prevê a inserção de stakeholders e opinion makers ${ }^{1}$ nos processos de design. (Moracce, 2009 apud Campos et. al. 2017, p. 2). Nesse cenário, a equipe de projeto possui um melhor entendimento do problema a ser solucionado ao conectar o conhecimento tácito dos usuários com o conhecimento técnico dos designers. (Vasconcelos \& Waechter, 2019, p. 3)

A fim de desenvolver um projeto cocriativo, com a participação dos stakeholders e opinion makers da marca, destaca-se a metodologia TXM Branding, desenvolvida pelo Laboratório de Orientação da Gênese Organizacional (LOGO), da Universidade Federal de Santa Catarina (UFSC), que segundo Campos et al. (2017, p.2) "visa representar a empresa como um todo antes mesmo da aplicação real de qualquer ação referente à marca", tendo como foco a assimilação da essência da marca.

A sigla "TXM" refere-se a três momentos distintos da metodologia (figura 1). A primeira etapa (Think) compreende o "pensar a marca". Neste momento, ocorrem pesquisas, levantamento de dados, observações, entrevistas a fim de definir conceitos que se desdobram no propósito e posicionamento da marca. Em sequência, a segunda etapa (eXperience) compreende a análise das informações coletadas previamente e a criação de experiências que transmitam sensorialmente a essência e a linguagem da marca com a intenção de aproximá-la de seu público e instigá-lo. E, por último, a terceira etapa (Manage) que se aproxima da área do marketing, na qual são desenvolvidas estratégias de gestão, como a criação de planos de comunicação, aplicação, definição de pontos de contato com seu público (interno e externo) e resolução de ações de curto, médio e longo prazo que visem a divulgação e crescimento da marca. O projeto apresentado neste artigo contempla apenas as duas etapas iniciais da metodologia $(T$ e $X)$, pois o laboratório optou por ter sua própria equipe responsável pelo desenvolvimento de estratégias de gestão da marca.

\footnotetext{
${ }^{1}$ No contexto do conteúdo apresentado neste artigo considera-se stakeholders aqueles que têm poder de decisão em relação ao projeto (cliente, presidente, equipe diretora, etc.) e opinion makers aqueles que podem expressar alguma opinião sobre o projeto (consumidores, terceirizados, colaboradores, etc.).
} 
Figura 1 - Diagrama TXM Branding

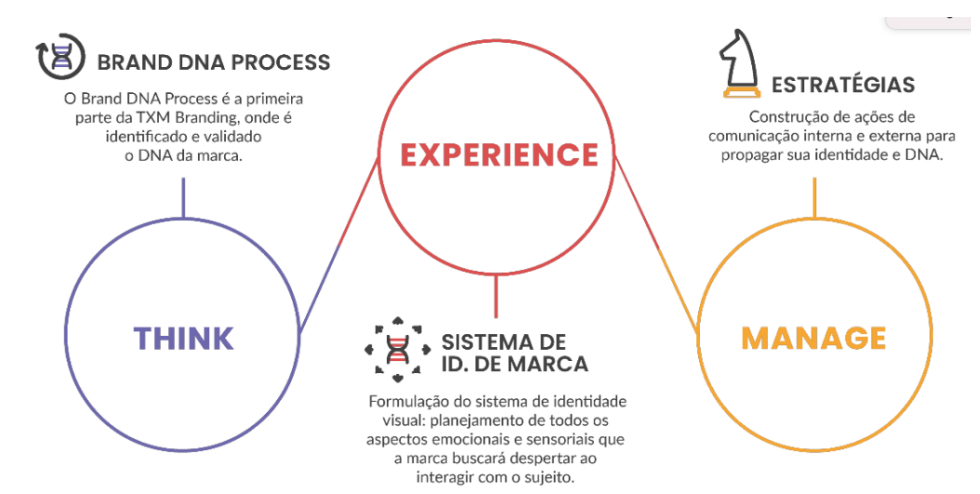

Fonte: LOGO (2017)

\section{Desenvolvimento: aplicação da TXM no design da marca do e-biotech}

O poder de uma marca foi ao longo do tempo ganhando cada vez mais espaço na sociedade do consumo, na qual as pessoas muitas vezes se relacionam mais com a marca em si do que com o produto, tornando-a, portanto, uma importante expressão de identidade para qualquer empresa. Dessa forma, a marca ultrapassa a barreira mercadológica e passa a ser adotada por cidades, instituições, eventos e organizações culturais. (Gibson, 2009, p. 69) A seguir é apresentado o desenvolvimento do projeto da marca para o e-biotech.

\section{Etapa Think: "Pensar a marca"}

A primeira fase teve a intenção de "pensar a marca", ou seja, realizar o estudo aprofundado e integrado de forma a compreender seu universo: características, mercado, produtos, potencialidades e desafios. As informações coletadas neste estágio proporcionam a conceituação da marca e, consequentemente, do projeto de marca. Fizeram parte desta etapa a realização de um diagnóstico, o evento criativo, a definição do propósito e do posicionamento.

\section{Diagnóstico}

Inicialmente, foi realizado o estudo sobre a marca com o objetivo de coletar informações relevantes que pudessem contribuir para o desenvolvimento da identidade visual do laboratório. Para isso foram realizadas pesquisas, entrevistas semiestruturadas, observações e análises que auxiliaram a compreender o funcionamento do laboratório. Os dados coletados, depois de analisados, tomaram a forma de uma análise SWOT. Dentre os resultados encontrados, foi possível destacar como vantagem o fato de o laboratório poder firmar parcerias a fim de melhorar seus processos e pesquisas, além de colaborar com outras instituições. Uma vulnerabilidade que enfrenta é que outros pesquisadores e comunidade sabem pouco sobre suas linhas de pesquisa. Pode, entretanto, defender-se ao buscar estreitar o relacionamento com outros laboratórios, já que possui um espaço preparado para a realização de pesquisas. Uma maior presença em eventos científicos e mercadológicos na área 
é uma forma de buscar essa visibilidade e formalizar parcerias. Depois de validado com o cliente, essas informações serviram de base para a realização do evento criativo.

\section{Evento criativo}

Para o evento criativo foi realizado um encontro entre stakeholders, opinion makers e equipe de projeto com o intuito definir o DNA da marca, que é a sua essência, aquilo que a diferencia de seus concorrentes (Gomez \& Stodieck, 2013). Os conceitos da marca são definidos a partir de 5 categorias, como mostra o quadro 1 .

Quadro 1: Categorias de conceito de DNA de marca - TXM Branding

\begin{tabular}{ll}
\hline Categoria & Finalidade \\
\hline Técnico & Remete diretamente ao produto/serviço oferecido pela marca. \\
Mercadológico & Relacionado ao modo como a marca se apresenta no mercado. \\
Emocional & Visa fidelizar todos que possuam algum contato com a marca. \\
Resiliente & $\begin{array}{l}\text { Remete à capacidade de se adaptar às adversidades, mantendo-se atualizado e } \\
\text { autêntico à sua essência. }\end{array}$ \\
Integrador & Integra as 4 categorias anteriores. \\
\hline
\end{tabular}

Fonte: LOGO (2017)

Para o e-biotech, foram definidos os seguintes conceitos da marca

- Técnico - INOVADOR: buscam por soluções inovadoras para problemas ambientais.

- Mercadológico - ESPECIALISTA: são referência em pesquisas de redução do impacto ambiental.

- Emocional - CONFIÁVEL: a transparência e lealdade são valorizadas em todos os relacionamentos, com pesquisadores, clientes e outros laboratórios.

- Resiliente - COLABORATIVO: refere-se ao modo como os membros do laboratório superam obstáculos e realizam suas pesquisas, em união.

- Integrador - ECO-FRIENDLY: descreve o foco das pesquisas, que buscam reduzir os danos socioambientais, com foco na renovação de resíduos.

\section{Propósito}

O propósito é uma força motivadora para as organizações que, segundo Reiman (2013, p. 29), proporciona às instituições ponderar, "não somente em dividir os lucros, mas também em repartir a responsabilidade por uma sociedade que funcione melhor". Dessa forma, esta ferramenta contribui para a percepção do papel que a marca desempenha na sociedade e no compromisso de entrega ao consumidor. Para definição do propósito foram respondidas as perguntas "o que seria do mundo sem você?" e "por que o e-biotech existe?". Ao final, o propósito definido para o e-biotech foi: Usar a ciência para promover sustentabilidade com menor impacto ambiental. 


\section{Posicionamento: persona}

Para definir o posicionamento, além de uma análise de concorrentes, foram definidas as personas, que são personagens arquetípicos fictícios, desenvolvidos para representar grupos de consumidores de uma marca. Sintetizam, portanto, o comportamento dos consumidores, representando suas motivações, desejos, expectativas e necessidades, buscando abranger características significativas daqueles que representam o público que a marca visa atingir. (Vianna et al. 2011, p. 80).

Dessa forma, a criação de personas ocorreu de forma sistemática, em cinco etapas, sendo elas: (i) identificar categorias de usuários do laboratório, no qual foram observados três grupos, aqueles que coordenam pesquisas, aqueles que as realizam e aqueles que as contratam; (ii) nomear os perfis das personas, em que foi constatado as figuras do professor, pesquisador de iniciação científica, pesquisador de pós-graduação e empresário; (iii) coletar informações referentes aos perfis identificados através de entrevistas, questionários semi estruturados e dados já levantados pelo laboratório; (iv) delinear os perfis com histórias, detalhes e contextos, de forma a tornar crível a participação dessas personas no dia a dia do laboratório; e, por último, validar as personas com os dados coletados e, posteriormente, com a equipe do laboratório. O quadro 2 apresenta as quatro personas desenvolvidas para o e-biotech.

Quadro 2: Personas do e-biotech

Descrição
Sandra Apolinaro tem 48 anos e é professora de engenharia química na
UFSC. Ela mora com o marido e sua filha em Coqueiros. Tornou-se
professora universitária por incentivo da mãe, que também atuava na área, e
pelo desejo de auxiliar na formação de outras pessoas. No dia a dia, se
dedica a ajudar os outros pesquisadores do laboratório em seus
experimentos e produções acadêmicas. Ela também procura constantemente
por editais e empresas parceiras, dispostas a financiar pesquisas de impacto
ambiental em seu tempo livre, Sandra procura por palestras interessantes na
internet no estilo TED Talks, e assiste a documentários na Netflix.
Matheus Braun tem 20 anos e é graduando em Engenharia Química na
UFSC. Ele mora na Trindade e divide apartamento com dois amigos do
curso. Escolheu a Engenharia Química por querer trabalhar com inovação e
por considerar o curso do futuro. Por estar na quarta fase, ainda não teve
oportunidade de estagiar em uma empresa, mas realizou disciplinas em
laboratório e se identificou muito com as atividades e pesquisas
desenvolvidas. Muito dedicado e comprometido com os estudos, é um dos
melhores alunos de sua turma e sempre se destaca nas provas e trabalhos
desenvolvidos. Matheus é descolado, adora fazer novas amizades e sair
com os amigos. Quando tem um tempo livre, procura fazer trilhas, atividades
ao ar livre e sempre está com um livro novo na mochila.



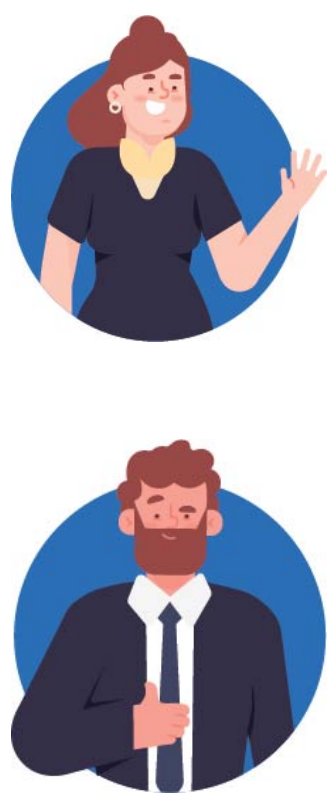

Rejanne Hoffmann tem 27 anos e é doutoranda em engenharia química na UFSC. Ela mora na Trindade e divide apartamento com sua gata Pelúcia. Seguiu carreira acadêmica por ser apaixonada por experimentos químicos e meio ambiente e sonha em se tornar professora e pesquisadora. Rejanne é uma líder nata e está sempre disposta a ajudar a todos no laboratório, seja auxiliando nos processos de pesquisa ou indicando artigos para produção científica. Ela acredita que "a união faz a força" e que, apenas juntos, podemos solucionar os problemas do mundo. Nas horas vagas, gosta de ir ao cinema com os amigos e ler livros de literatura clássica.

César Schutz tem 34 anos e é sócio de uma empresa de bens de consumo. Ele mora em São Paulo com a família, mas está sempre viajando a trabalho; Como sócio, ele participa das decisões importantes da empresa, levantando a bandeira da inovação para que seja destaque no mercado. Possui uma preocupação constante em diminuição de custos e no melhor controle do descarte, tratamento e valorização dos resíduos, considerando que as leis ambientais trazem penalidades graves para aqueles que as descumprem. César está sempre em busca de parcerias e procuram, nas universidades, laboratórios que possam criar melhorias para seu negócio. Em seu tempo livre, ele gosta de viajar e assistir a filmes de ação e aventura.

Fonte: autores

A criação das personas auxiliou na identificação de necessidades e demandas dos diferentes públicos do laboratório, assim como, na avaliação das alternativas geradas na segunda fase do projeto, a fim de selecionar as mais promissoras.

\section{Etapa Experience: "Experienciar a marca"}

A segunda etapa da TXM Branding compreende a tradução das pesquisas realizadas e informações apuradas na etapa Think, ou seja, consiste na construção da marca gráfica. (Leite, 2016, p. 74). Assim, foram realizadas experimentações gráficas usando como premissa o DNA da marca, definido na fase anterior: inovador, especialista, confiável, colaborativo e eco-friendly.

A princípio, foi realizada uma análise da antiga identidade visual do laboratório sob a ótica do design, observando seus elementos (símbolo e logotipo): (a) o formato circular do símbolo pretende evidenciar o aspecto das pesquisas realizadas e sua coloração remete ao seu viés sustentável, enquanto (b) o logotipo, construído a partir de duas tipografias (com e sem serifa), apresenta a antiga nomenclatura do laboratório. Ao observar a composição da marca, nota-se a carência de harmonia entre o símbolo e o logotipo, além de problemas de legibilidade devido à concentração de diversos elementos em uma única área. Ademais, há a necessidade de atualização do naming e tagline da marca. 
Figura 2: antiga identidade visual do e-biotech

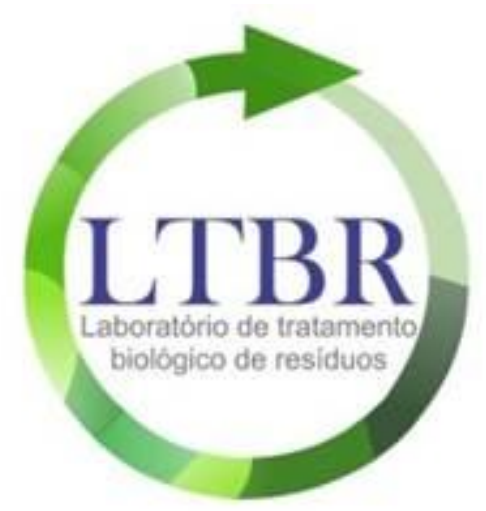

Fonte: e-biotech (2020)

A fim de corrigir os problemas encontrados após a análise da antiga marca do laboratório, notou-se a necessidade da criação de um painel de tema ou conceito visual que segundo Pazmino (2015, P. 162) pode ajudar na "definição e visualização do significado do produto [neste caso, da marca] para facilitar na geração de alternativas a criação de estilo do produto", definindo aspectos semânticos e simbólicos. Dessa forma, foram gerados três painéis visuais (figuras 3, 4 e 5), que variam em conteúdo e finalidade, conforme mostra o quadro 3.

Quadro 3: Relação de painéis visuais

\begin{tabular}{lll}
\hline Painel visual & Conteúdo & Finalidade \\
\hline Formas & $\begin{array}{l}\text { Figuras que traduzem em seus traços, } \\
\text { contornos e moldes o conceito de ciclo e } \\
\text { renovação }\end{array}$ & $\begin{array}{l}\text { Estabelecer diretrizes para o } \\
\text { símbolo da marca }\end{array}$ \\
Cores & $\begin{array}{l}\text { Posters que trazem cores relacionadas ao meio } \\
\text { ambiente } \\
\text { Tipografia }\end{array}$ & $\begin{array}{l}\text { Auxiliar na escolha de uma } \\
\text { Posters com diferentes estilos tipográficos cores para a marca }\end{array}$ \\
& & $\begin{array}{l}\text { Propor um estilo para a grafia } \\
\text { do nome do laboratório }\end{array}$ \\
\hline
\end{tabular}

Fonte: autores 
Figura 3: painel de formas

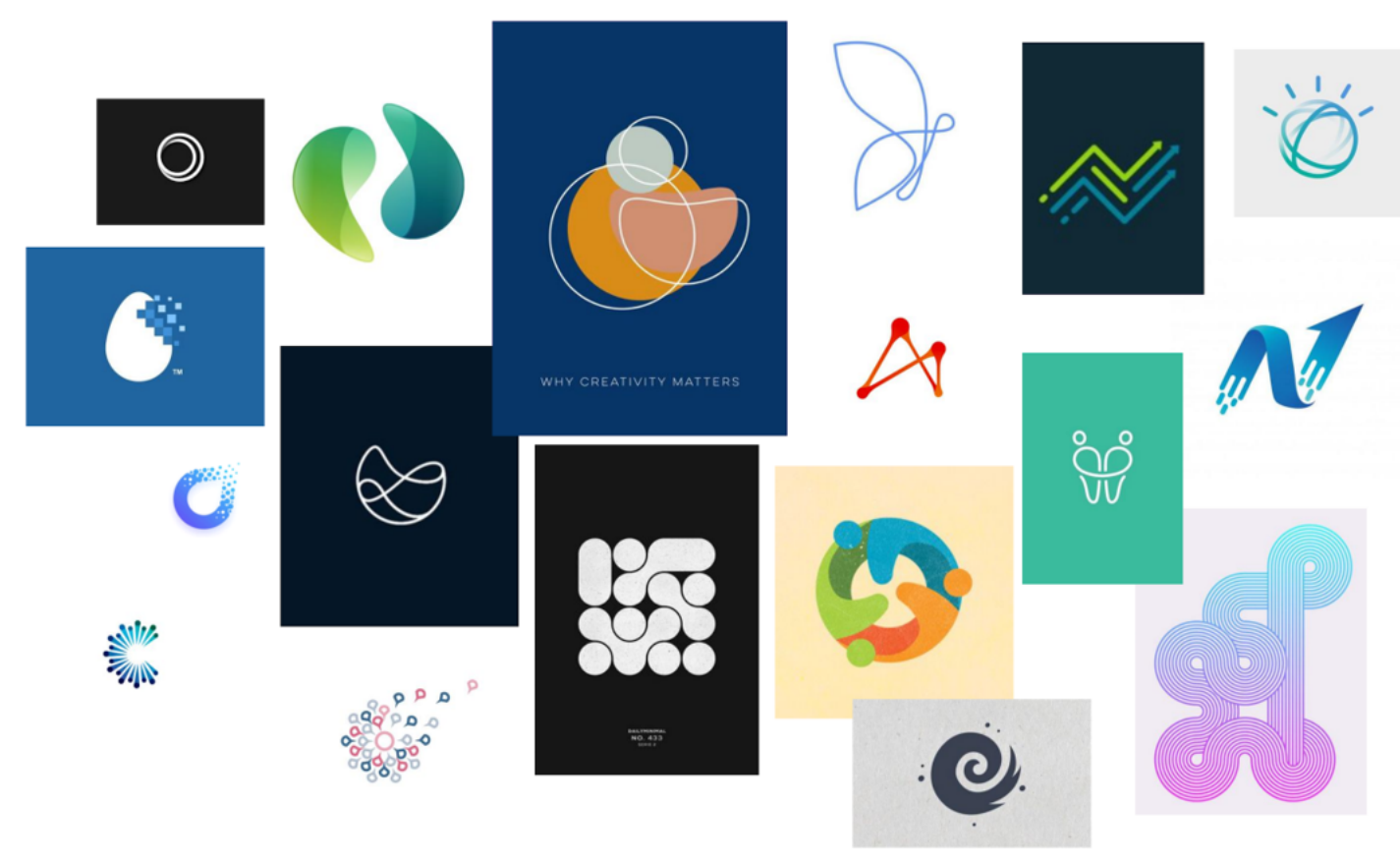

Fonte: autores

Figura 4: painel de cores
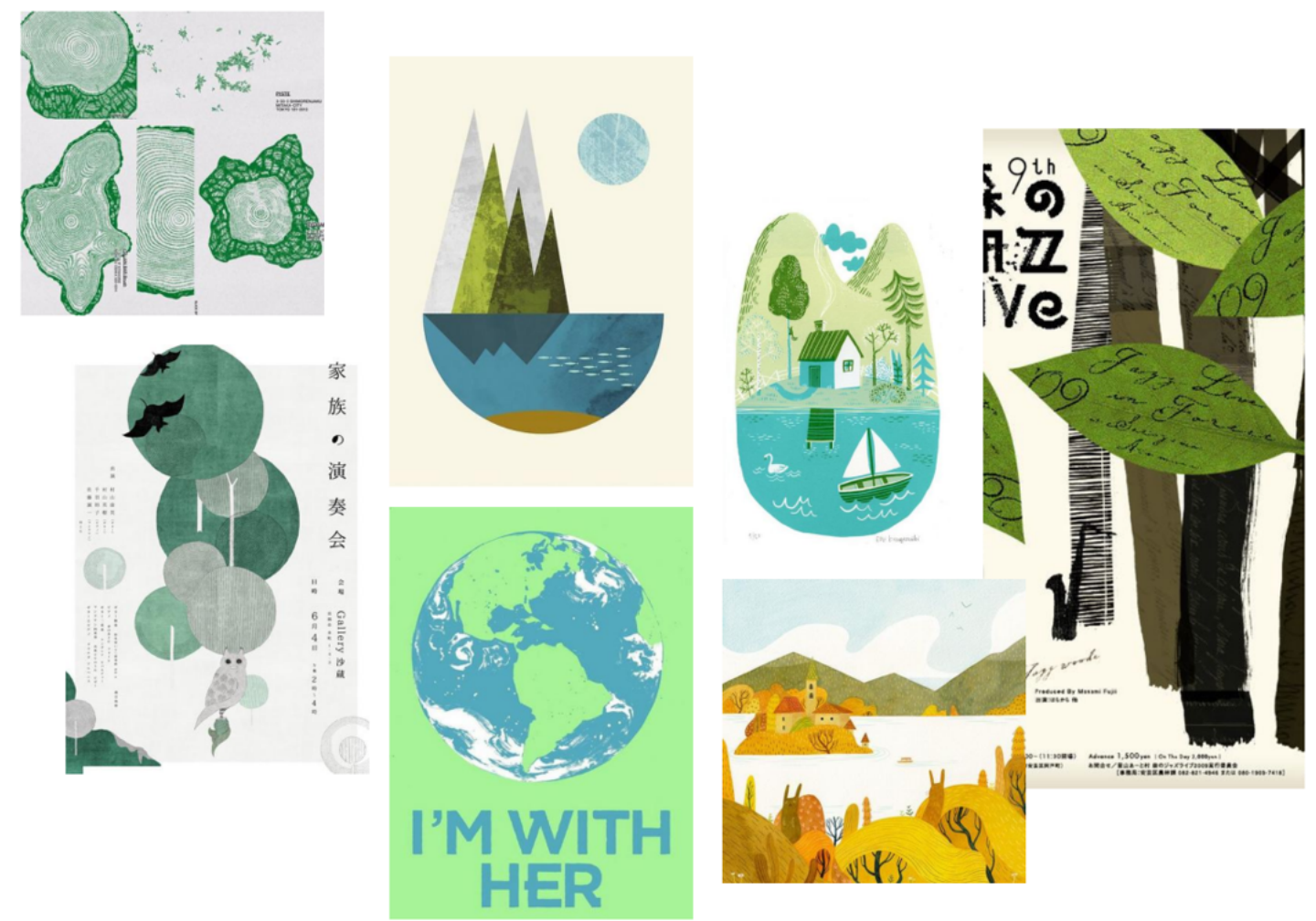

Fonte: autores 
Figura 5: painel de tipografias

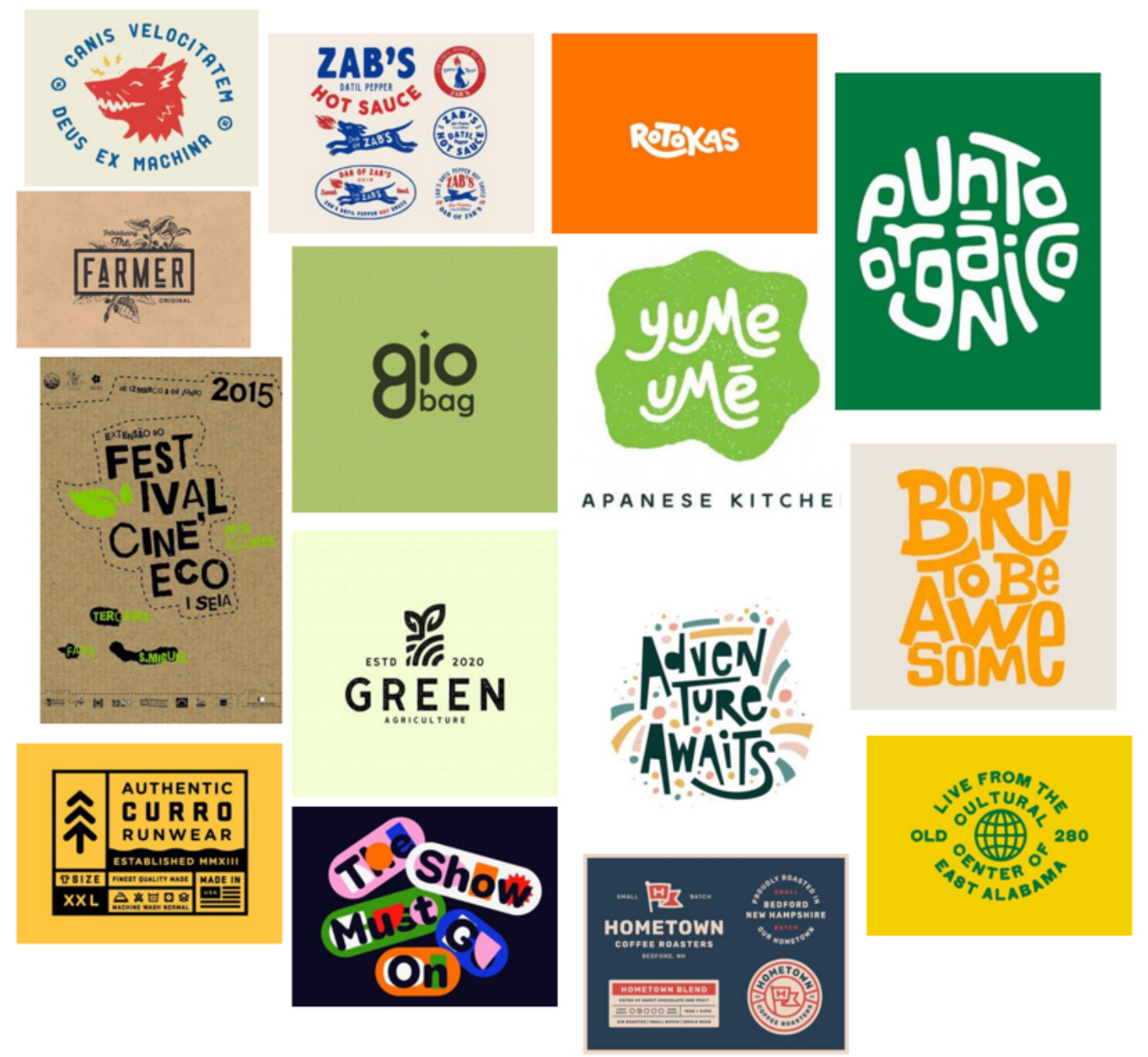

Fonte: autores

\section{Geração de alternativas}

Com suporte dos painéis visuais, foi iniciada a construção dos elementos gráficos da marca. De forma a complementar a metodologia e dinamizar essa etapa, optou-se por aplicar o método de brainwriting 635 , uma técnica colaborativa que envolve diversos participantes para geração de ideias de forma descontraída.

O procedimento básico subjacente ao Método 635 é que seis designers desenvolvam e escrevam três ideias dentro de um período de tempo definido de três a cinco minutos antes de passar suas ideias para o vizinho ou designer subsequente. Na próxima etapa, cada membro da equipe deve desenvolver ideias com base nas ideias fornecidas por seu predecessor. Isso pode acontecer por meio da modificação de ideias existentes ou até mesmo do desenvolvimento de novas ideias inspiradas nas ideias dadas. Esse procedimento é continuado até que cada membro da equipe receba sua folha inicial de ideias, o que deve acontecer após cinco rodadas considerando 6 participantes. (Rohrbach, 1969 apud Schröer et. al. 2010, p. 592)

A aplicação do método originou 75 alternativas, sendo selecionadas as três propostas que melhor representavam o laboratório para refinamento e vetorização (figura 6). A primeira traz 
uma proposta mais literal do ramo do laboratório, com um símbolo de folha para representar o cuidado com o meio ambiente. A segunda opção apresenta um formato dinâmico, aparentando um movimento circular, que representa os ciclos de inovação do laboratório. E, por último, a terceira alternativa que visa representar o laboratório e suas pesquisas de forma abstrata.

Figura 6: vetorização das melhores propostas para símbolo
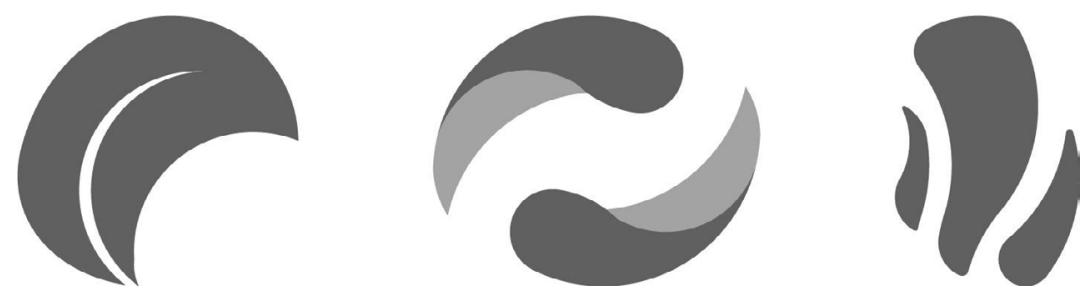

Fonte: autores

Criação da assinatura visual

A proposta escolhida foi a segunda opção por representar o nicho de mercado do laboratório e receber aprovação de seus membros. A marca apresenta potencial visual de aplicação em diversos suportes e o seu símbolo possui forte conexão com a ideia de inovação, algo considerado essencial para um laboratório que desenvolve estudos com foco na diminuição dos impactos ambientais. A partir disso, foi dado início a seleção das cores institucionais com o objetivo de encontrar aquela que melhor expressasse o DNA da marca. Segundo Wheeler (2008, p. 118), a cor tem a capacidade de "evocar emoções, lembranças, estimular sentidos e é de extrema importância na identidade visual".

Para a paleta de cores do e-biotech foram definidos dois tons de azul como cores principais da marca, devendo estar presentes em seu símbolo. A escolha do azul foi feita pelo fato da coloração marcar presença na natureza, ramo de atuação do laboratório. (figura 7)

Figura 7: cores institucionais da marca

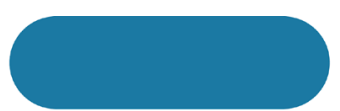

$$
\begin{gathered}
\text { C:86 M:45 Y:21 K:2 } \\
\text { R:28 G:120 B:161 } \\
\text { \#1C78A1 }
\end{gathered}
$$

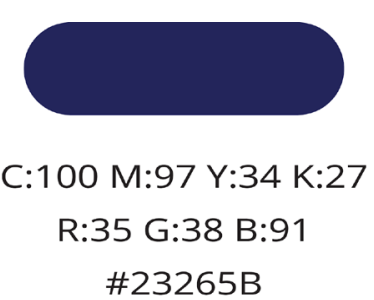

\#23265B

Fonte: autores

No logotipo, a sigla do laboratório foi concebida em caixa baixa e a partir da tipografia Nunito Sans modificada, a fim de tornar os caracteres mais arredondados do que sua versão original. Entende-se que tal configuração melhor representa o DNA da marca ao transmitir leveza e confiabilidade, características presentes no laboratório. A tagline foi adotada por caráter explicativo, para explicitar o significado da sigla do laboratório e proporcionar maior visibilidade à marca. A figura 8 apresenta a marca do e-biotech em sua versão final. 
Figura 8: composição final da marca

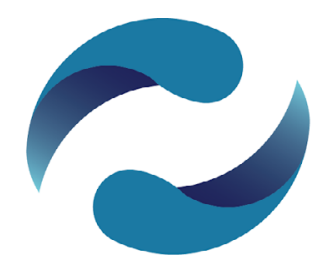

\section{e-biotech}

Laboratório de

Biotecnologia Ambiental

Fonte: autores

Os objetivos do projeto de marca, identificados no contato inicial com a equipe do e-biotech, relacionavam-se a seu uso em eventos científicos nacionais e internacionais e na conquista de novas parcerias e acordos com a iniciativa privada e outros laboratórios universitários. $O$ fator cocriativo presente na TXM Branding, possibilitou a criação de uma marca coesa para o laboratório e correspondia às expectativas de seus pesquisadores.

\section{Considerações finais}

O vínculo estabelecido entre uma empresa e seu público-alvo é resultado da união entre Design da Informação e Design de Identidade Visual, ao passo que compete ao primeiro promover a assimilação da informação e, ao segundo, contribuir para a identificação e diferenciação das marcas no mercado. A aplicação do método TXM modificado foi fundamental para garantir um processo criativo e ordenado que fizesse jus aos eixos do design compreendidos neste processo de criação.

O resultado do projeto foi decorrência da coleta, compreensão e curadoria das informações obtidas, tarefa desempenhada na etapa Think, e posterior síntese visual em forma de marca gráfica das informações apuradas, atividade executada na etapa eXperience. Dessa forma, equilibrando os aspectos gráfico-visuais e informacionais, obteve-se uma marca que apresenta de forma clara e expressiva o real significado do laboratório. Por fim, entendendo a importância de manter o funcionamento da marca de acordo com seu DNA e essência, a equipe do laboratório ficou responsável por aplicar a etapa Manage, criando estratégias e realizando a gestão da marca em suas diferentes plataformas e diante da comunidade científica, fazendo com que se perpetue no mercado. Assim, no que diz respeito a este projeto, suas atividades com a marca encontram-se encerradas.

Destaca-se como um dos diferenciais do projeto o fato de que o processo de construção da marca e seu posterior resultado final permite a promoção, não apenas do laboratório, lugar esse que promove a construção do saber e da ciência, como também de pesquisas que 
buscam alcançar resultados que impactem positivamente a sociedade, democratizando deste modo o ensino e o conhecimento.

\section{Agradecimento}

Os autores agradecem o apoio recebido pelo Fundo de Apoio à Manutenção e ao Desenvolvimento da Educação Superior (FUMDES) pelo financiamento à pesquisa e também ao Programa de Pós-Graduação em Design da UFSC.

\section{Referências}

Campos, A; Gomez, L \& Pilatti, G. (2017). A experiência de marca da metodologia TXM associada ao Visual Merchandising: os pontos de venda da marca Farm Rio. Convergências: Revista de Investigação e Ensino das Artes, 10(19), 1-6.

Costa, V. S. da. (2016, setembro). Divulgação científica no Youtube e o mundo midiatizado da ciência. Anais do Congresso Brasileiro de Ciências da Comunicação, São Paulo, SP, Brasil, 39.

Frascara, J. (2004). Communication Design: Principles, methods and practice. New York: Allworth Press.

Freitas, R. F de; Coutinho, S. G \& Waechter, H da N. (2013). Análise de Metodologias em Design: a informação tratada por diferentes olhares. Estudos em Design, 21 (1), 1-15.

Gibson, D. (2009). The wayfinding handbook: Information design for public places. New York: Princeton Architectural Press.

Gomez, L. S. R \& Stodieck, W. F. (2013). O fator DNA: ferramentas a favor da construção de marcas diferenciadas. Convergências: Revista de Investigação e Ensino das Artes, 11(6), $1-13$.

Leite, A. M. Y. (2016). Metodologia TXM Branding aplicada à construção de marca da mind the graph. [Monografia]. Departamento de Comunicação e Expressão, Universidade Federal de Santa Catarina, Florianópolis.

Lipovetsky, G. (2016). Da leveza: Para uma civilização do ligeiro. Coimbra: Edições 70.

LOGO. (2017). Metodologia. Laboratório de Orientação da Gênese Organizacional. http://logo.ufsc.br/

Pazmino, A. V. (2015). Como se cria: 40 métodos para design de produtos. São Paulo: Editora Blucher.

Peón, M. L. (2003). Sistemas de Identidade Visual. Rio de Janeiro: 2AB.

Quintão, F. S. \& Triska, R. (2013). Design de informação em interfaces digitais: origens, definições e fundamentos. Revista Brasileira de Design da Informação, 10(2), 105-118.

Raposo, J \& Moura, M. (2019). Design da informação e design de identidade: busca por convergência para a construção de espaços sensoriais demarca. Anais do Congresso Internacional de Design da Informação e do Congresso Nacional de Iniciação Científica em Design da Informação, Belo Horizonte, MG, Brasil, 9. 
Reiman, J. (2018). Propósito: por que ele engaja colaboradores, constrói marcas fortes e empresas poderosas. Rio de Janeiro: Alta Books Editora.

SBDI. (2006). Definições. Sociedade Brasileira de Design da Informação. https://sbdi.org.br/definicoes

Schröer, B; Kain, A \& Lindemann, U. (2010). Supporting creativity in conceptual design: method 635-extended. International Design Conference, Dubrovnik, Croácia, 11.

Strunck, G. L. (1989). Identidade visual: A direção do olhar. São Paulo: Editora Europa.

Sutil, B. V; Facin, G. \& Feijó, V. C. (2019). Branding e Teatro: Desenvolvimento de Diagnóstico de Marca para a Escola de Teatro Casanova. Anais do Congresso de Ciências da Comunicação na Região Sul, Porto Alegre, RS, Brasil, 20.

Vasconcelos, O \& Waechter, H. (2019). Design de identidade visual participativo: Uma proposta metodológica para o design de marcas com o usuário. Anais do Congresso Internacional de Design da Informação e do Congresso Nacional de Iniciação Científica em Design da Informação, Belo Horizonte, MG, Brasil, 9.

Wheeler, A. (2008). Design de identidade da marca: Guia essencial para toda a equipe de gestão de marcas. Porto Alegre: Bookman Editora.

\section{Sobre os autores}

Caio Fraile Gonçalves, Mestrando, PPGDesign/UFSC, Brasil <caiofraile@gmail.com>

Marília Matos Gonçalves, Dra., UFSC, Brasil <marilinhamt@gmail.com>

Berenice Santos Gonçalves, Dra., UFSC, Brasil <berenice.s.g@ufsc.br> 